\title{
Médiévales
}

Langues, Textes, Histoire

63 | automne 2012

Philosophies morales

\section{Patricia EICHEL-LOJKINE (dir.), Claude de Seyssel, Écrire l'histoire, penser le politique en France, à l'aube des temps modernes}

Rennes, Presses Universitaires de Rennes, 2010, 266 p. (Coll. Histoire)

\section{Xavier Pindard}

\section{OpenEdition}

\section{Journals}

Édition électronique

URL : https://journals.openedition.org/medievales/6902

DOI : $10.4000 /$ medievales. 6902

ISSN : 1777-5892

\section{Éditeur}

Presses universitaires de Vincennes

Édition imprimée

Date de publication : 15 décembre 2012

Pagination : 178-180

ISBN : 978-2-84292-353-2

ISSN : 0751-2708

\section{Référence électronique}

Xavier Pindard, «Patricia eichel-Lojkine (dir.), Claude de Seyssel, Écrire l'histoire, penser le politique en France, à l'aube des temps modernes ", Médiévales [En ligne], 63 | automne 2012, mis en ligne le 15 janvier 2013, consulté le 23 avril 2022. URL : http://journals.openedition.org/medievales/6902 ; DOI : https://doi.org/10.4000/medievales.6902

Ce document a été généré automatiquement le 23 avril 2022

Tous droits réservés 


\section{Patricia EICHEL-LOJKINE (dir.), Claude de Seyssel, Écrire l'histoire, penser le politique en France, à l'aube des temps modernes}

Rennes, Presses Universitaires de Rennes, 2010, 266 p. (Coll. Histoire)

Xavier Pindard

1 Cet ouvrage consacré à Claude de Seyssel (c. 1450-1520) est le fruit des travaux d'un colloque organisé en mars 2008 par Patricia Eichel-Lojkine, également co-responsable d'une publication des Louenges du roy Louys XIIe de ce nom du même Seyssel. Constatant la faiblesse des écrits d'importance consacrés à Claude de Seyssel depuis les travaux pionniers de Jacques Poujol en 1960, les auteurs entendent dresser un panorama très large des œuvres mais aussi de l'existence de celui qui fut à la fois un conseiller de Louis XII, un traducteur d'œuvres antiques, un humaniste et un auteur politique de premier plan, souvent comparé à Machiavel et More.

2 Les contributions émanent d'historiens, d'historiens du droit et de spécialistes de littérature, médiévistes et modernistes, et sont rassemblées autour de trois parties distinctes. Dans un premier temps, c'est la conception de la monarchie française que défend Seyssel qui est étudiée. Tenant du régime mixte aristotélicien, qui mêle harmonieusement des éléments monarchiques, aristocratiques et démocratiques comme le rappelle A. Jouanna, Seyssel veut limiter le pouvoir monarchique par des « freins» (religion, justice, police), dont U. Langer nous montre l'origine italienne. Son discours n'a que peu à voir avec une pensée constitutionnelle, puisque selon Seyssel la limitation du pouvoir royal ne peut venir en dernier ressort que du roi lui-même, qui doit se comporter avec modération.

3 Dans sa réflexion, largement utilitariste et pragmatique, Seyssel accorde une place importante à la noblesse (L. Bourquin). Constatant le déclin de la noblesse ancienne depuis la guerre de Cent Ans et les empiètements du pouvoir royal sur le pouvoir aristocratique, il insiste sur l'importance pour le roi de s'appuyer sur la noblesse pour 
renforcer le pouvoir de l'État, et de permettre l'accès à la noblesse des plus méritants et des plus dévoués au service du roi.

4 Les contributions de F. Collard et de J. Blanchard permettent de replacer Seyssel dans son contexte d'écriture en le rapprochant respectivement de Robert Gaguin et Philippe de Commynes. Les similitudes constatées sont certes assez nombreuses, aussi bien avec Gaguin sur le rejet de la tyrannie du roi qu'avec Commynes sur la crainte des factions et de la guerre civile, mais les divergences révèlent l'originalité de Seyssel: auteur pragmatique mais plus abstrait et imprégné de philosophie que Commynes ; auteur politique surtout attentif au présent et à la dynamique de la monarchie, à l'opposé d'un Gaguin préoccupé surtout de son maintien en l'état au nom d'un passé glorieux idéalisé. Certes imprégné des valeurs de la fin du Moyen Âge, Seyssel se rattache déjà à la Renaissance et à la modernité.

5 La deuxième partie de l'ouvrage revient sur quelques aspects de la pensée politique de Claude de Seyssel, mais envisage également sa réflexion sur la société dans son ensemble, les deux aspects étant intimement liés dans la vision que l'évêque de Marseille développe de la monarchie française. Confronté aux transformations de la société de son époque, il a en effet envisagé la mobilité sociale comme un phénomène de grande ampleur, que le prince doit encourager (N. Hochner). Seyssel conçoit la société comme un ensemble de trois ordres, selon un modèle original inspiré de l'Italie qui exclut le clergé, pour retenir la noblesse, le peuple gras et le peuple menu. Entre ces trois ordres, il est nécessaire de favoriser la fluidité et la circulation pour donner un espoir au peuple, et le roi se doit d'intervenir pour réguler le passage du deuxième au premier ordre en choisissant les hommes vertueux pour le service de l'État. Seyssel conçoit également les trois ordres comme des concurrents, mais, reprenant à son compte la théorie des humeurs, il voit le corps politique comme un corps humain qui ne peut se maintenir en vie que par la circulation des différentes humeurs.

6 M. Clément prolonge la réflexion sur la mobilité sociale et le corps politique chez Seyssel. Au contraire d'un auteur comme Du Bellay qui envisage dans son Discours des quatre estats de 1559 la mobilité comme négative, Seyssel insiste sur les mérites de chaque individu plus que sur le sang et la race. De plus, il voit dans la possibilité de changer d'état non seulement un espoir pour les individus, mais aussi une source d'émulation qui crée des richesses pour le royaume, l'État se contentant de jouer un rôle de protection des catégories qui pourraient être lésées. En insistant sur le rôle de l'État administratif et de l'économie de marché, Seyssel jette donc les bases d'un capitalisme catholique, fortement influencé par la réalité italienne, avant même la naissance du protestantisme.

7 J.-L. Fournel et P. Eichel-Lojkine s'intéressent ensuite à l'écriture de Seyssel et à sa finalité. Comparant la Monarchie de France et le Prince, J.-L. Fournel note que Seyssel, comme Machiavel, compose des traités en langue vulgaire sur la politique, bien différents des miroirs des princes traditionnels. L'étude de l'usage d'un vocabulaire parfois imprécis, parsemé de doublons, révèle des ouvrages écrits rapidement pour répondre à l'urgence de la situation politique créée par les guerres d'Italie. P. EichelLojkine se penche plus spécifiquement sur les Louenges du roy Louys XIIe de ce nom, récit proche des mémoires qui relate majoritairement ce dont Claude de Seyssel a été témoin. Elle propose de reconsidérer ce texte inspiré des panégyriques aux empereurs romains, qu'on a longtemps considéré comme une simple œuvre de courtisanerie envers le souverain en place. Seyssel, comme Érasme à la même époque avec Philippe le 
Beau, ne cherche pas tant à flatter le souverain qu'à lui indiquer la voie à suivre en le poussant à se conformer à son modèle littéraire, alors que l'historiographie n'a pas encore rompu avec le modèle du panégyrique.

Enfin, J.-M. Constant s'attache à retracer la postérité du modèle de la monarchie tempérée en France sous l'Ancien Régime, alors même que l'absolutisme s'impose. Trois modèles de monarchie tempérée émergent en réalité: d'abord, un premier, le plus proche de Seyssel, qui insiste sur les freins et sur le rôle des cours souveraines pour tempérer la monarchie. Puis un deuxième plus radical, celui des monarchomaques et des ligueurs, voulant conférer des pouvoirs considérables aux États Généraux pour contrôler le roi, et qui tombe en discrédit à la mort d'Henri IV. Et enfin un modèle plus littéraire, celui de L'Astrée, qui valorise la liberté et l'absence de contraintes, idéal de nobles devenus bergers et imprégnés de philosophie stoïcienne. Au-delà des différences, la référence aux freins revient cependant toujours, illustration de la longévité de la pensée seyssélienne.

9 La dernière partie, «le diplomate, l'humaniste, le juriste », plus disparate, complète les deux premières en éclairant d'autres aspects du personnage de Claude de Seyssel. C'est d'abord le juriste, formé à Pavie et auteur d'un traité sur les fiefs évoqué rapidement (F. A. Goria), qui est mis en avant. M.-F. Renoux-Zagamé confronte le discours de Seyssel sur le frein de justice, par lequel les cours souveraines brident la précipitation d'un prince irréfléchi, à la réalité de la pratique judiciaire de son temps, en particulier au Parlement de Paris. Les convergences font apparaitre Seyssel comme un observateur averti du mécanisme de l'enregistrement des lettres patentes et des remontrances par le Parlement, réalité juridique qui se développe à son époque et devient incontournable pendant tout l'Ancien Régime.

P. Torrens s'intéresse, lui, aux traductions de textes latins ou grecs (à partir des traductions latines de son ami grec Lascaris) menées par Seyssel. Il note que ces traductions, bien que souvent fautives ou imprécises, ont incontestablement nourri la pensée de Seyssel, qui donne volontiers des exemples tirés de l'Antiquité et plus particulièrement de la République romaine dans ses écrits politiques, mais sans toutefois jamais idéaliser le passé antique.

11 Humaniste et écrivain, Seyssel fut aussi un homme d'action, dont Louis XII tira profit lors de diverses missions diplomatiques. $\mathrm{L}$. Vissière retrace toutes ces ambassades dans l'espace alpin lors des années 1508-1514, moment de grave crise pour la monarchie française. Ces missions compliquées, et parfois risquées puisque Seyssel fut sur le point d'être enlevé à Berne, ont alimenté la Monarchie de France, où apparaît la préoccupation de conserver le royaume et ses frontières.

12 L'ouvrage se clôt sur deux études, celle de C. Michon sur les frères Du Bellay, exemple d'une historiographie immédiatement postérieure à Seyssel et bien différente, et celle de B. Beys consacrée aux images de Seyssel dans les manuscrits de ses œuvres: on y voit un homme puissant, à l'aura internationale, qui se met en scène comme donateur de son ouvrage à Louis XII évidemment, mais aussi à divers princes européens.

13 La très grande diversité des contributions, avec parfois des redites inévitables dans une publication collective, éclaire de nombreux aspects de la vie et du travail intellectuel de Claude de Seyssel, personnage de premier plan délaissé par l'historiographie française depuis plusieurs décennies. Tout en faisant la part belle à la réflexion politique, sociale et économique du conseiller de Louis XII, pour laquelle il est resté fameux, ses autres 
activités intellectuelles et politiques ne sont pas laissées dans l'ombre, dressant le portrait foisonnant et passionnant d'un grand humaniste français de la Renaissance. 